\title{
Investigation of Transient Performance for a Sublimator
}

\author{
Rubik B. Sheth ${ }^{1}$ and Ryan A. Stephan. ${ }^{2}$ \\ National Aeronautics and Space Administration, Houston, TX, 77058 \\ and \\ Thomas O. Leimkuehler ${ }^{3}$ \\ Paragon Space Development Corporation, Houston, TX, 77058
}

\begin{abstract}
Sublimators have been used as heat rejection devices for a variety of space applications including the Apollo Lunar Module and the Extravehicular Mobility Unit (EMU). Sublimators typically operate with steady-state feedwater utilization at or near $100 \%$. However, sublimators are currently being considered to operate in a cyclical topping mode during low lunar orbit for Altair and possibly Orion. The cyclical topping mode represents a new mode of operation for sublimators. In this operational mode, the sublimator will be repeatedly started and stopped during each orbit to provide supplemental heat rejection for the portion of the orbit where the radiative sink temperature exceeds the system setpoint temperature. This paper will investigate the effects of these transient starts and stops on the feedwater utilization for various feedwater timing scenarios.
\end{abstract}

$\begin{array}{lll}u & =\text { Utilization } & \text { Nomenclature } \\ \dot{m}_{i} & =\text { Ideal sublimation rate } \\ \dot{m}_{a} & =\text { Actual sublimation rate } \\ Q & =\text { Energy } \\ \Delta h & =\text { Heat of Vaporization } \\ \text { OAFU } & =\text { Orbit Averaged Feedwater Utlization } \\ t & =\text { time step } \\ \mathrm{m}_{\text {reservoir }} & =\text { Amount of Water in Reservoir } \\ \text { Tset } & =\text { System Set Point Temperature }\end{array}$

\section{Introduction}

$\mathrm{R}$ ejecting heat is a critical requirement for any space vehicle or habitat. For certain mission scenarios, a sublimator provides an attractive option for heat rejection. For example, a sublimator can be used to supplement radiators for handling peak heat loads, or a sublimator can be used exclusively for heat rejection in some environments where the use of radiators is unfeasible. A sublimator rejects heat by using the process of sublimation, which is when a substance, such as water, changes from the solid phase directly to the vapor phase. Sublimators have been used for heat rejection in a variety of space applications, such as the Apollo Lunar Module and the Extravehicular Mobility Unit (EMU) ${ }^{1}$. Currently, sublimators are being considered to be used in a cyclical fashion for topping purposes by Altair and Orion.

\footnotetext{
${ }^{1}$ Project Engineer, Crew and Thermal Systems Division, 2101 Nasa Road 1 EC2

${ }^{2}$ Project Manager for Advanced Thermal Control Technologies, Crew and Thermal Systems Division, 2101 Nasa Road 1 ECl

${ }^{3}$ Senior Aerospace Engineer, 1120 NASA Parkway, Suite 505, Non-member..
} 
The lunar surface temperatures vary widely, ranging from 400 Kelvin at the sub solar point to less than 100 Kelvin on the cold side as shown in Figure 1. Due to this large variation in surface temperatures, a vehicle's radiative environment changes considerably throughout the orbit. For this analysis, it was assumed that the spacecraft was orbiting the moon at a 100 kilometer circular orbit with a beta angle of $0^{\circ}$. The period for this orbit is approximately two hours. Close to the sub solar point, the thermal control system is unable to achieve the desired set point using only a radiator for heat rejection, therefore the vehicle must rely on a supplemental heat rejection device (SHReD). Depending on the mission duration, either an evaporative heat sink, including a sublimator, or a phase change material heat exchanger (PCMHX) can be used as a SHReD. Sublimators are considered to be the most mass efficient for short mission durations when compared to PCMHX. The Altair thermal control system design relies on a sublimator for heat rejection during both Lunar ascent and descent. Because the hardware is already included in the system design and the LLO duration is relatively short, a sublimator has been chosen as the $\mathrm{SHReD}^{2}$. Figure 2 shows the relationship between radiator capability and the sublimator requirement. In this figure, the sublimator requirement is simply the difference between the radiator capability and the vehicle heat rejection requirement. A sublimator has never been used to provide heat rejection in a cyclic fashion as required in low lunar orbit.

\section{Coupon Level Testing}

Initially coupon level tests were performed to understand basic sublimator performance under a cyclical heat load. ${ }^{3}$ The coupon tests were also completed to assess the growth of the ice layer during periods of low applied heat loads. The project was concerned with hardware failure due to the expansion of ice. Furthermore, under cyclical heat loads, various feedwater timing scenarios were evaluated for the sublimator. Two primary objectives were sought from this small scale test, an assessment of a sublimator's Orbit Averaged Feedwater Utilization (OAFU) for the various feedwater timing scenarios and an understanding of sublimator structural stability with increased ice growth within the

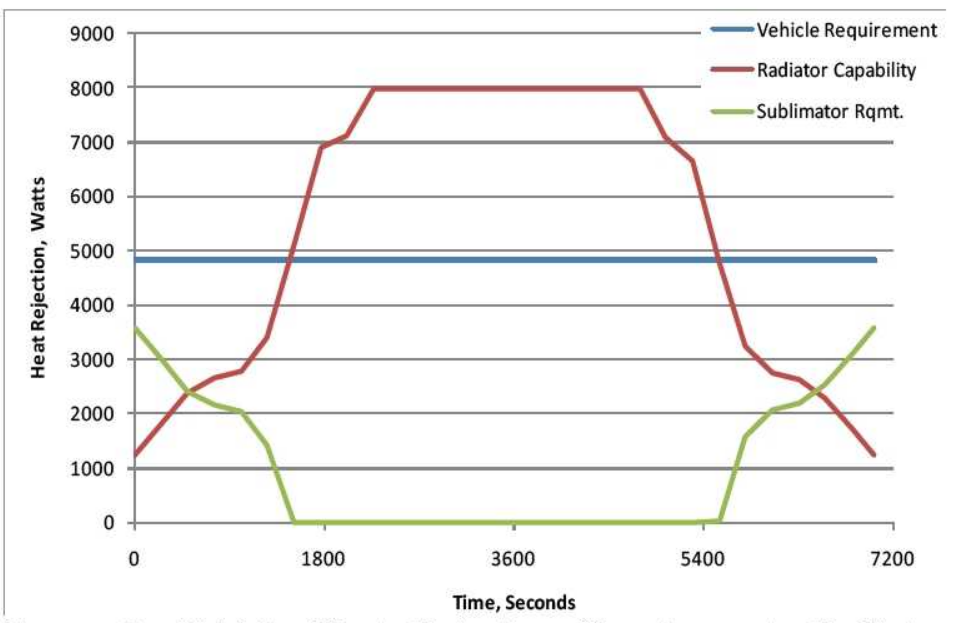

Figure 2. Vehicle Heat Rejection Requirement, Radiator Capability, and Supplement Heat Rejection Requirement for a Lunar Orbit

\section{sublimator.}

Generally, a sublimator's feedwater efficiency is quantified by calculating utilization for a steady state heat load by using Equation (1). Here a theoretical value for the feedwater flowrate is divided by the actual flowrate of feedwater used by the sublimator for an applied heat load. This equation is in terms of mass flow rates at a particular instant in time. This equation is not useful for calculating the feedwater efficiency of a sublimator exposed to a varying heat load. Instead, the OAFU can be quantified by integrating the feedwater mass flowrate with respect to time over the course of a single lunar orbit. The actual mass of feedwater consumed, $\mathrm{m}_{\mathrm{a}}$, is still calculated using the amount of water used by a sublimator for a single orbit. The ideal mass of feedwater consumed, $\mathrm{m}_{\mathrm{i}}$, is now evaluated using the time varying supplemental heat rejection requirement of the sublimator for a single orbit. The relationship for OAFU is shown in Equation (2). 


$$
\begin{aligned}
& u=\frac{\dot{m}_{i}}{\dot{m}_{a}} \text {, where } \dot{m}_{i}=\frac{Q}{\Delta h} \text { (1) } \\
& O A F U=\frac{m_{i}}{m_{a}} \text {, where } m_{i}=\int_{\text {oneorbit }} \dot{m}_{i} d t=\int_{\text {one orbit }} \frac{Q}{\Delta h} d t
\end{aligned}
$$

Initially, the X-38 sublimator was planned to be used for performance testing under cyclical heat loads. However, due to the aforementioned risk of ice growth within the sublimator, a test coupon was fabricated to mimic the performance of the X-38 Sublimator. Figure 3 below shows a cut away schematic and photograph of the coupon.

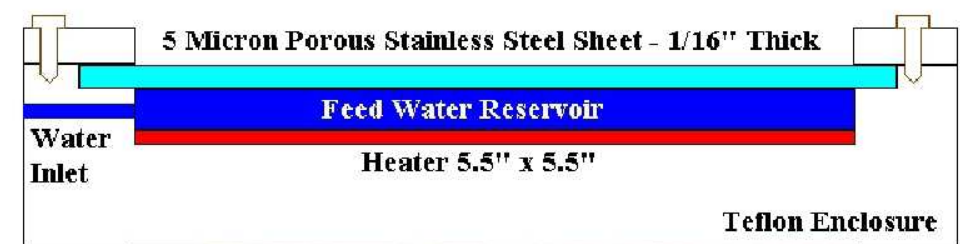

The coupon was fabricated using a 1/16inch thick, five micron porous stainless steel sheet as the sublimation surface. Below the porous plate is the feedwater layer filled with low density aluminum foam. The foam helped in decreasing the thermal resistance between the heat source and sublimation surface. Below the foam was a 5.5 inch by 5.5 inch aluminum plate with a heater attached to the back side. The heater plate replicates the heat load applied by the warm coolant loop present in the flight hardware. A power supply was used to simulate the heat load induced on a sublimator during typical transient scenarios. The entire coupon is encapsulated with a thick Teflon enclosure to minimize parasitic

Figure 3. Transient Sublimator Coupon Design and Photograph heat transfer.

Figure 4 shows the feedwater loop and the location of the test coupon in the vacuum chamber. Deionized and degassed water is supplied from a feedwater tank. The feedwater is supplied to the sublimator through the use of an in-line isolation valve. Before entering the sublimator, the feedwater passes through a pressure regulator, which is used to maintain the feedwater pressure at 3 psia. For diagnostic purposes, a pressure transducer is included downstream of the regulator to record the water pressure at the sublimator inlet. Furthermore, a flow meter was used to record the flow rate of the feedwater throughout the test point. The feedwater tank was located on a scale. Mass readings from this scale were used to calculate the sublimator's OAFU. Labview was used to record all of the instrumentation and to control the coupon's heater. Figure 5 is a plot of the applied heat load during a nominal test day. One can see how the transient heat load was applied for approximately 45 minutes, and for the remainder of the simulated two-hour orbit, the heater was turned off. This scaled heating cycle was derived from the $\mathrm{SHReD}$ requirement shown in Figure 2.

One of the test objectives was to quantify the relationship between timing the feedwater isolation valve and the coupon's OAFU. One possibility to consider is to keep the feedwater isolation valve open for the entire orbit. During the periods of zero heat load on the sublimator, just as it does during normal operation, the presence of the ice layer in the sublimator would prevent the feedwater from rushing out into

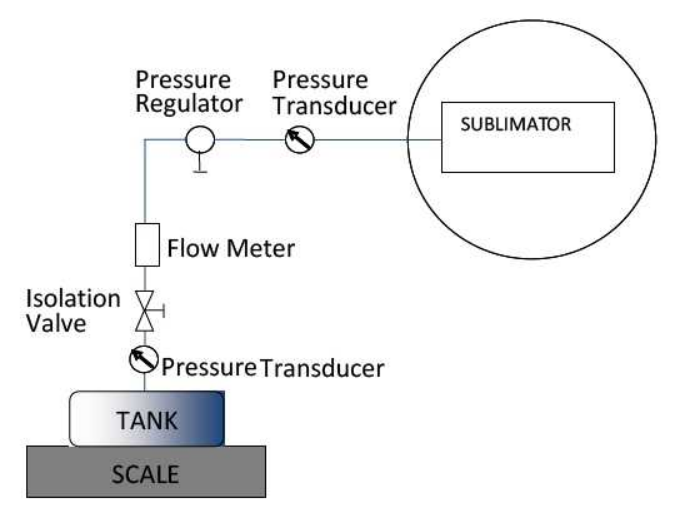

Figure 4. Transient Sublimator Coupon Test Loop Design

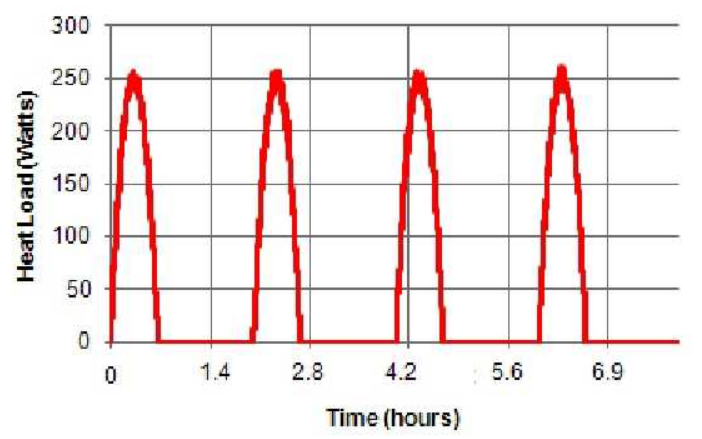

Figure 5. Transient Sublimator Coupon Applied Heat Load for a Test day

American Institute of Aeronautıcs and Astronautıcs 
space. However, even without an active heat load applied to the sublimator, the ice layer is still exposed to space vacuum, and would therefore continue to sublimate slowly, possibly wasting feedwater and lowering the OAFU. To avoid this, the feedwater isolation valve could possibly be closed before the transient heat load goes to zero in an attempt to sublimate away all of the feedwater remaining in the sublimator so that it is empty during the periods of zero heat load. However, getting the timing just right would be tricky. In order to investigate whether the timing of the feedwater isolation valve actuation has any affect on OAFU, the present test program was undertaken.Over the course of the test program, five different feedwater control scenarios were completed. Each scenario changed the time interval for which the feedwater supply was sent to the test coupon. This in turn achieved the goal of quantifying the performance of the sublimator. Each test scenario was performed with an applied, maximum heat load of either 200 or 250 Watts $\left(6.6\right.$ or $\left.8.3 \mathrm{~W} / \mathrm{in}^{2}\right)$. The five test scenarios are summarized below. For clarity, a graphical representation is shown in Figure 6:

- $\quad$ No Close - Never close the feedwater supply valve during test

- $\quad$ Start/End - Open and close feedwater supply valve at the beginning and end of each 40 minute heating cycle respectively.

- 5 minutes prior - Open the feedwater supply valve at the beginning, and close the feedwater supply valve 5 minutes prior to the end of each heating cycle

- 10 minutes prior - Open the feedwater supply valve at the beginning, and close the feedwater supply valve 10 minutes prior to the end of each heating cycle

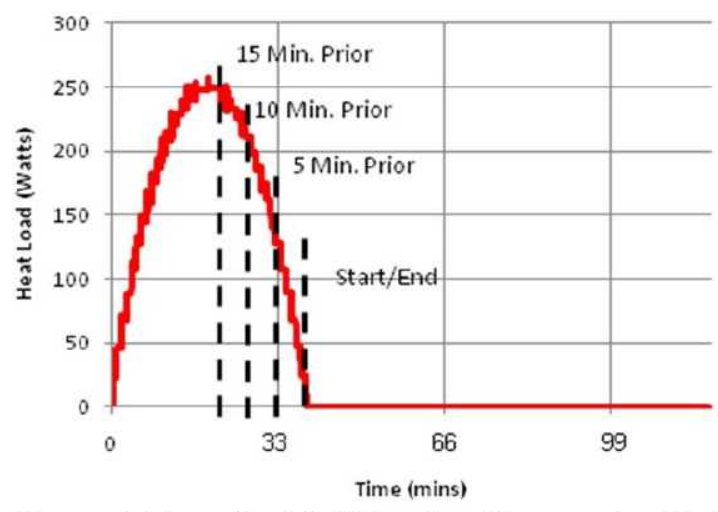

Figure 6. Transient Sublimator Coupon Applied Heat Load for a Test day

- 15 minutes prior - Open the feedwater supply valve at the beginning, and close the feedwater supply valve 15 minutes prior to the end of each heating cycle

The time interval to close the feedwater valve 15 minutes prior to the end of the heating cycle was determined by solving for $t_{i}$ in Equation 3. The rationale for this approach is that the ideal time to close the feedwater isolation valve is when the mass of feedwater in the reservoir from downstream of the isolation valve to the porous plate in the sublimator is just enough to reject the remaining energy to be rejected in the transient heat load profile. For this particular test coupon and test setup, using Equation (3), it was determined that the isolation valve controlling the feedwater to the sublimator should be closed 15 minutes prior to the end of the heating cycle. Additional test points were included to close the valve at 5 and 10 minutes prior to the end of the heat cycle to investigate the effect of this timing.

$$
m_{\text {reservoir }}=\int_{t_{i}}^{t_{f}} \frac{Q}{\Delta h} d t \text { (3) }
$$

A summary of the Transient Sublimator Coupon Test data is shown in Table 1 for each feedwater control scenario. For a given day, an orbit was run multiple times and an OAFU was calculated for each orbit. To ensure data repeatability, each scenario was tested at least twice. The OAFU data shown in Table 1 represents the average of all the OAFUs for the given scenario. Furthermore, due to the fact that sublimator temperatures were becoming periodic after the first orbit of a test day, the data for first orbit was deemed an outlier and disregarded.

Table 1. Summary of Coupon Level Testing OAFU in Respect to Feedwater Control

\begin{tabular}{|c|c|}
\hline $\begin{array}{c}\text { Feedwater Control } \\
\text { Scenarios }\end{array}$ & $\boldsymbol{O A F U}$ \\
\hline No Close & $88 \%$ \\
\hline Start/End & $93 \%$ \\
\hline 5 Min. Prior & $97 \%$ \\
\hline 10 Min. Prior & $100 \%$ \\
\hline 15 Min. Prior & $105 \%$ \\
\hline
\end{tabular}

From the data in Table 1, there is an apparent trend between the timing of the feedwater isolation valve actuation and the OAFU. It appears that leaving the feedwater isolation valve open longer results in a lower OAFU. For example, leaving the feedwater valve open all the time ("No Close") resulted in an OAFU of only $88 \%$. Closing the 
feedwater isolation valve before the transient heat load goes to zero in order to minimize residual feedwater left in the sublimator resulted in an OAFU at or near $100 \%$. This supports the hypothesis that leaving feedwater in the sublimator during the periods of zero heat load allows for continued feedwater sublimation, wasted feedwater, and therefore lower OAFU. In order to verify whether these coupon-level test results are applicable to a full-scale flight sublimator, a continued experimental investigation is planned.

\section{Future Plans for X-38 Sublimator Transient Testing}

\section{A. Test Article}

The current state of the art in sublimator technology is the sublimator designed by Hamilton Sundstrand for the previously planned X-38 Crew Return Vehicle ${ }^{1}$. The X-38 sublimator evolved from the Lunar Module 209 sublimator design, having a design heat load capacity of approximately $10 \mathrm{~kW}(35,000 \mathrm{Btu} / \mathrm{hr})$ with water as the coolant at an inlet temperature of $108^{\circ} \mathrm{F}\left(42.2^{\circ} \mathrm{C}\right)$ and a flow rate of $500 \mathrm{lb} / \mathrm{hr}(0.063 \mathrm{~kg} / \mathrm{sec})$. A picture of the X38 sublimator is shown in Figure 7. Hot coolant enters the sublimator through a manifold, where the flow is divided among 6 double sided and 2 one sided sublimation plates. Coolant enters the middle flow passage on each sublimator plate, depicted as the red layer in Figure 8 . Once the coolant moves through the sublimator the flow combines in another manifold and exits the opposite side of the sublimator. Another inlet manifold allows feedwater to enter the sublimator and is split into two layers on each sublimator plate, depicted as the blue sections in Figure 8. The feedwater freezes, since it is subjected to a vacuum environment, and the energy from the hot coolant causes the ice to sublimate, carrying away heat from the coolant.

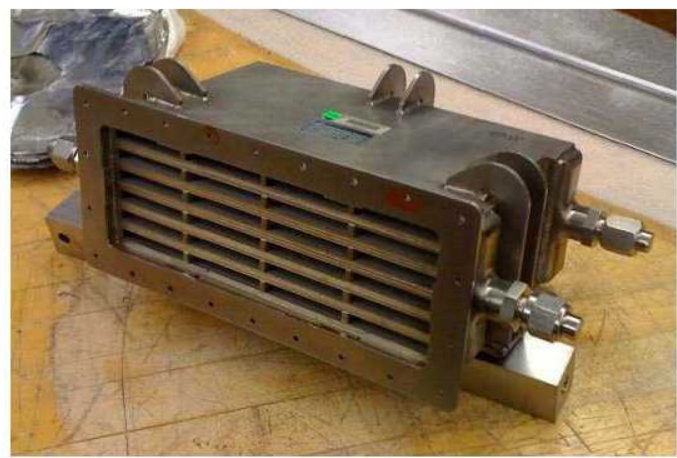

Figure 7. X-38 Sublimator

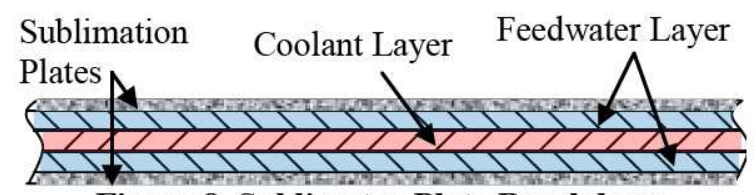

Figure 8. Sublimator Plate Breakdown The two grey layers sandwiching the coolant and feedwater layers in Figure 8 are the sublimation surfaces.

\section{B. Test Requirements and Test Loop Architecture}

Test requirements were derived using an Altair heat rejection requirement of $4.8 \mathrm{~kW}(16,800 \mathrm{Btu} / \mathrm{hr})$, while maintaining a system return temperature, or set point temperature, of $50^{\circ} \mathrm{F}\left(10^{\circ} \mathrm{C}\right)$. Furthermore, due to the large variations in lunar surface temperatures, as seen in Figure 1, the sink temperature experienced by the radiators on Altair varies during Low Lunar Orbit. The analysis was performed for a two hour orbit with a beta angle of $0^{\circ}$, resulting in a radiative sink temperature varying between $-350^{\circ} \mathrm{F}\left(-213^{\circ} \mathrm{C}\right)$ to $62^{\circ} \mathrm{F}\left(17^{\circ} \mathrm{C}\right)$. Moreover, the radiators for this analysis were sized for lunar surface operation while neglecting thermal mass. Nonetheless, due to the large variation in sink temperatures, the outlet temperature of the coolant from the radiator varies during the two hour orbit. The relatively warm sink temperature experienced at the sub solar point, corresponding to the red area in Figure 1, results in loss of the system set point temperature therefore requiring supplemental heat rejection by the sublimator. The following architectures outline the various sublimator placements within a vehicle to provide this supplemental heat rejection.

The objective of testing the X-38 sublimator is to assess its performance when used as a SHReD under cyclical heat loads, and to see whether the trends observed in the coupon testing will be evident with this full-size sublimator. There are several system architecture and operational options for using a sublimator in this manner. The first option investigates the sublimator response when the sublimator is installed immediately downstream of the radiator. This means coolant is constantly flowing through it during all portions of the mission. A simplified schematic of the system architecture is shown in Figure 9. The heat source represents all the energy acquired by the coolant loop from coldplates, cabin air heat exchanger, and other heat acquisition equipment within the vehicle. The green three way valve is used to proportion the coolant flow so that a constant set point temperature (Tset) of $50^{\circ} \mathrm{F}\left(10^{\circ} \mathrm{C}\right.$, $283 \mathrm{~K}$ ) can be maintained entering the cabin. The graph below the system schematic shows the coolant inlet temperature and flow rate into the sublimator, which is essentially the coolant exit condition from the radiator. This 
plot shows that supplemental heat rejection is required approximately 50 minutes into the Lunar orbit because the radiator cannot maintain the system setpoint. It is important to note that the analysis assumes constant feedwater within the sublimator during the two hour orbit. This results in a constant flow rate through the sublimator since it is assumed that a coolant temperature of $32^{\circ} \mathrm{F}\left(0^{\circ} \mathrm{C}\right)$ exits the sublimator at all times. A constant bypass flow mixes with the flow exiting the sublimator to provide a constant setpoint temperature.

A second option calls for the sublimator at the same location as configuration 1 , but with a bypass valve around it to allow for diverting the coolant flow around the sublimator when a SHReD is not needed. This results in no flow through the sublimator for about 90 minutes of the two hour orbit during which supplemental heat rejection is not needed. A schematic of this system architecture is shown in Figure 10. The schematic is essentially the same as in Figure 9, with the addition of the bypass line around the sublimator. The resulting coolant inlet conditions to the sublimator can be seen in the corresponding graph. During the portions where

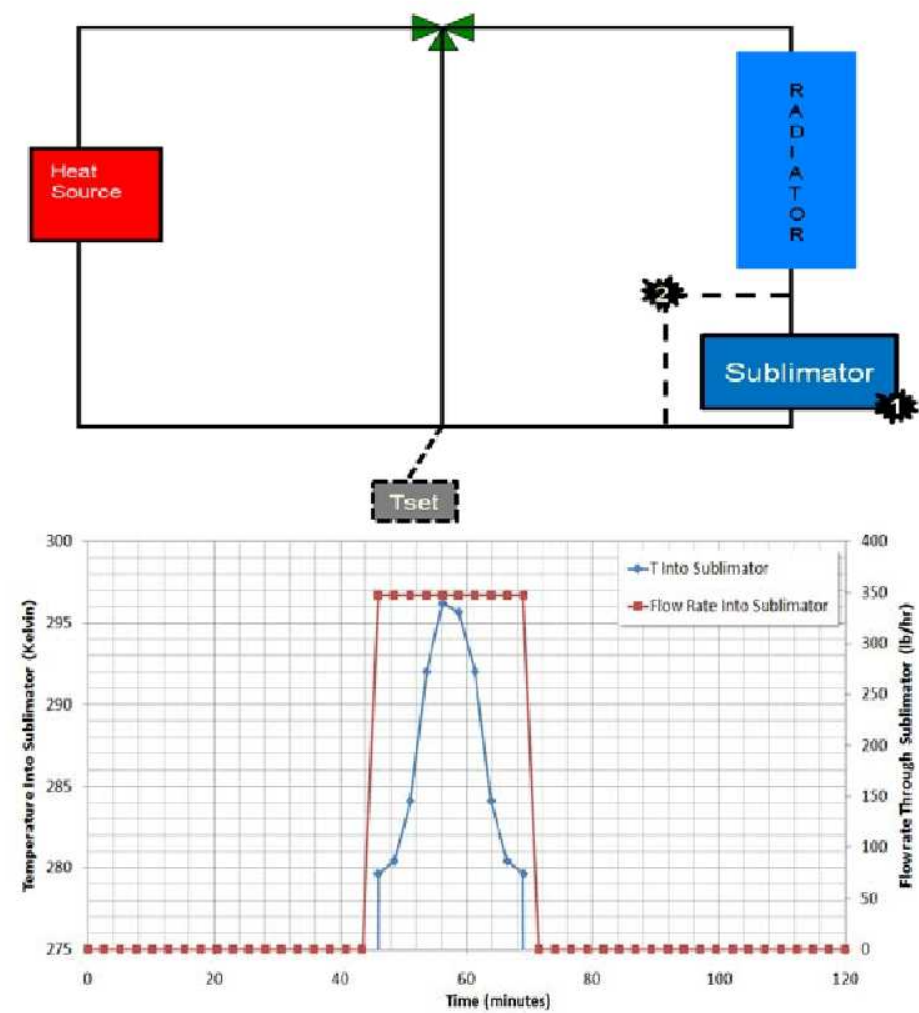

Figure 10. Sublimator Configuration 2 Schematic and Inlet Temperature/Flowrate to Sublimator Graph
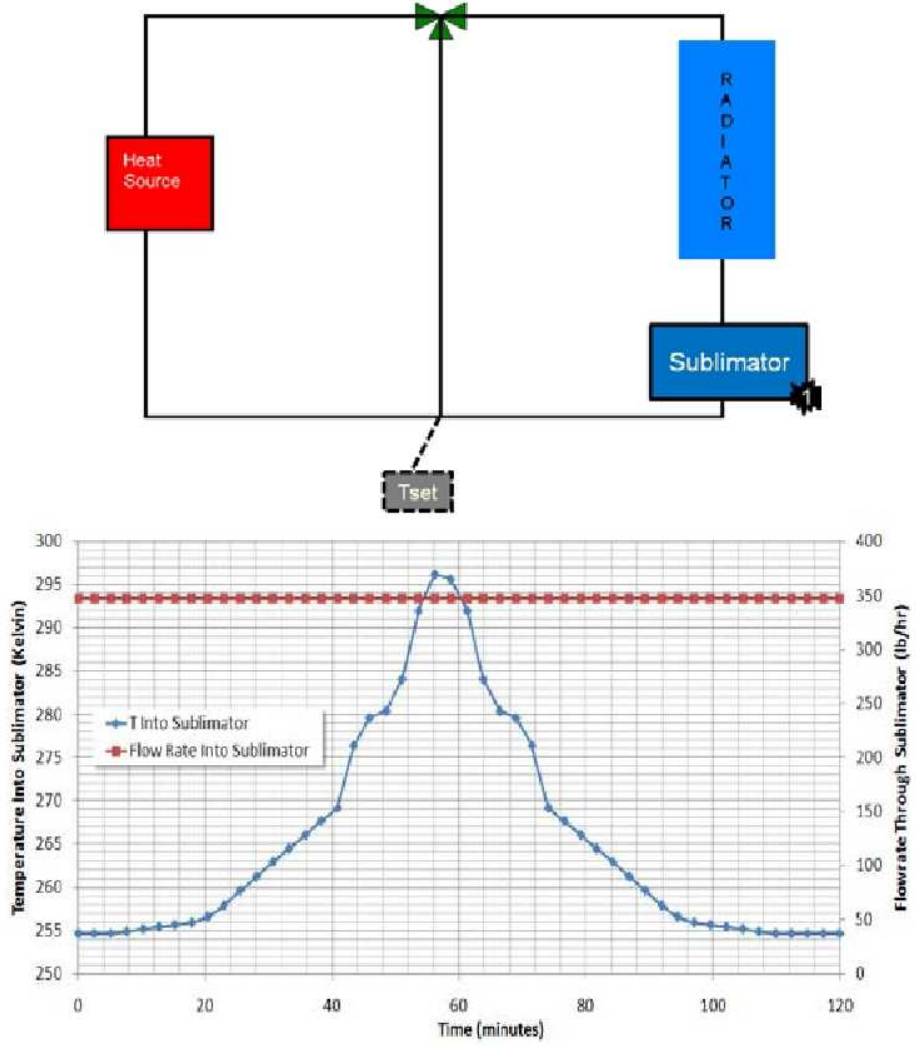

Figure 9. Sublimator Configuration 1 Schematic and Inlet Temperature/Flowrate to Sublimator Graph

no supplemental heat rejection is needed, zero flow is sent to the sublimator since the bypass valve diverts the flow around the sublimator. During the portions where the sublimator is providing supplemental heat rejection, the flow and inlet temperature profile are the same as in configuration 1 .

A final option investigates installation of the sublimator downstream of where the radiator and bypass lines join. This third architecture allows the sublimator to be used after the radiators are detached from the flight vehicle. Scenarios when this would occur include the ascent phase of Altair, when the ascent module detaches from the decent module where the radiators are located, or when Orion separates from the service module when returning to Earth. During nominal operations, when a radiator can be used as the sole means of heat rejection, the original proportioning valve can be used to control the system set point temperature. Nonetheless, due to the fact that the set point location of the coolant loop is located after the sublimator when a SHReD is required, another proportioning valve is needed to ensure the required set point of $283 \mathrm{~K}$ is met entering the cabin. Simplified loop 

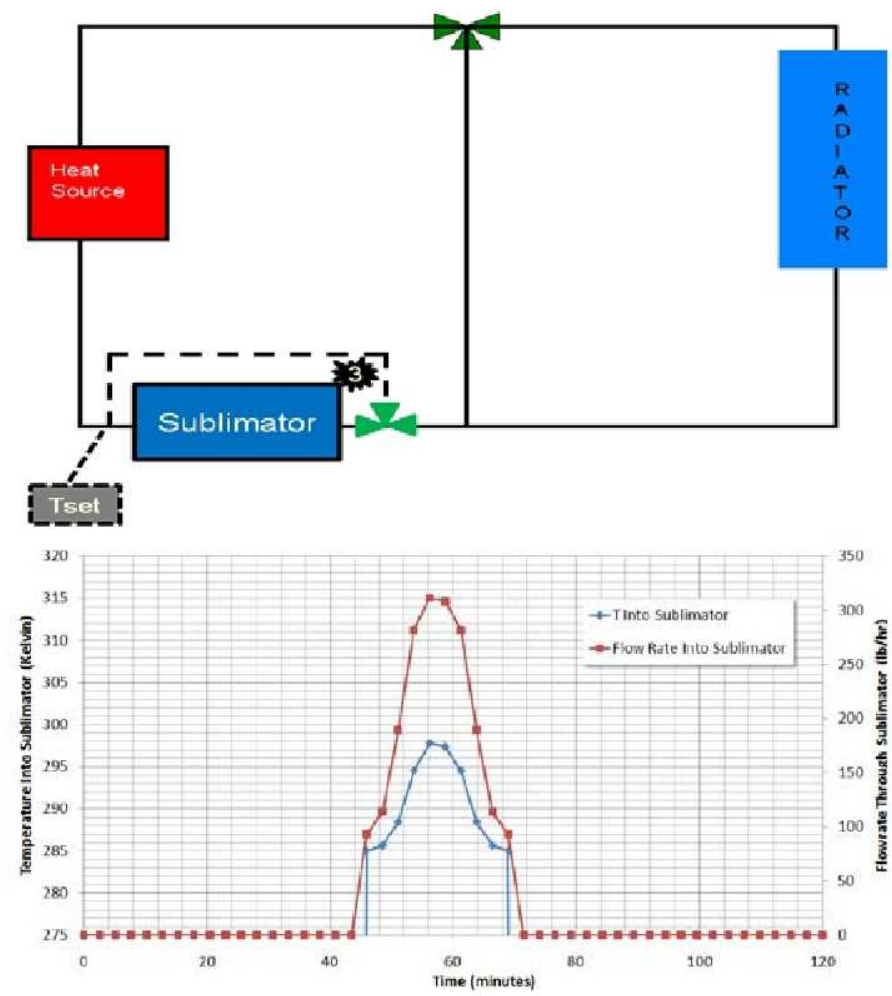

Figure 11. Sublimator Configuration 3 Schematic and Inlet Temperature/Flowrate to Sublimator Graph

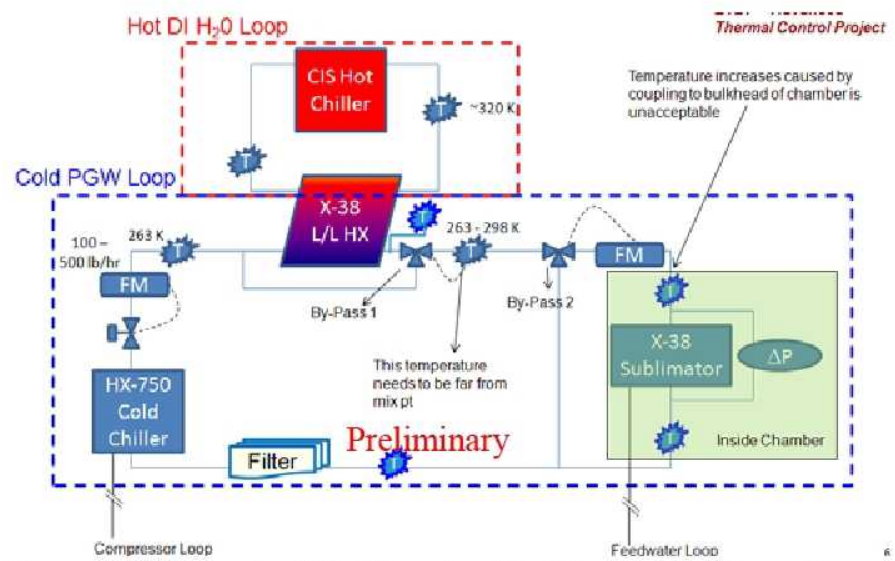

Figure 12. Transient Sublimator Test Loop Configuration

architecture for this configuration is shown in Figure 11. Due to the fact that the set point temperature (Tset) is required to be maintained at $50^{\circ} \mathrm{F}\left(10^{\circ} \mathrm{C}\right)$, the flowrate through the sublimator varies with time in order to provide the proper amount of supplemental cooling. This results in a varying coolant flowrate and temperature through the sublimator for the 30 minute duration when a SHReD is needed.

These three sublimator architectures resulted in the test coolant loop architecture shown in Figure 12. This test architecture allows for varying coolant flow rates and temperatures into the sublimator for the two hour orbit.

Feedwater control is performed using the isolation valve on the feedwater loop. The same feedwater architecture as seen in Figure 4, used for the sublimator coupon, will be used for the $\mathrm{X}-38$ sublimator testing. Furthermore, the same variations to feedwater control are planned for the $\mathrm{X}-38$ testing as were performed during the sublimator coupon testing. By using the X-38 sublimator feedwater reservoir volume and Eq. 3 , an optimal time will be determined for which enough water would be left in the sublimator feedwater loop and reservoir to reject the remainder of the heat load during a heating cycle. This is essentially using the same logic as used during coupon level tests.

\section{Conclusion}

Subjecting a sublimator to a cyclical transient heat load is a new concept and has never been performed before on a flight vehicle. Coupon level tests were performed using cyclical heat loads based on Altair Lunar Lander requirements with a transient heat load applied to the sublimator for about 35 minutes and the heat load removed for the remainder of the two hour simulated lunar orbit. This heating cycle was repeated several times over the course of a test day. The purpose of these tests was to investigate whether feedwater valve timing has any effect on OAFU. Additionally these coupon tests evaluated whether growth of the ice layer during extended periods of zero heat load would cause structural damage. Post-testing inspections did not reveal any such damage to the sublimator coupon. However, the testing results appear to indicate that leaving the feedwater isolation valve open longer results in a lower OAFU.

These coupon tests have paved the path for, and demonstrated the need to begin work on, performing higher fidelity tests on flight-like sublimator hardware. The sublimator designed and built for the X-38 will be used for this testing. This sublimator will be tested under similar cyclical heat loads, but scaled to an appropriate magnitude for the size of the hardware, and with a coolant loop to apply the necessary heat loads. The sublimator inlet conditions (temperatures and flowrates) will be determined using Altair requirements. 


\section{References}

1. Tongue, S., Dingell, C., "The Porous Plate Sublimator as the X-38/CRV (Crew Return Vehicle) Orbital Heat Sink," 29th International Conference on Environmental Systems, SAE Paper 1999-012004, 1999.

2. Stephan, R. A., "Overview of NASA's Thermal Control System Development for Exploration Project," SAE Paper 2009-01-2436, 39th International Conference on Environmental Systems, 2009.

3. Leimkuehler, T. O., Sheth, R., Stephan, R. A., "Investigation of Transient Sublimator

Performance," 39th International Conference on Environmental Systems, SAE Paper 2009-012480, 2009. 